\title{
Avenacin Production in Creeping Bentgrass (Agrostis stolonifera) and Its Influence on the Host Range of Gaeumannomyces graminis
}

\author{
S. L. Thomas and P. Bonello, Department of Plant Pathology, The Ohio State University, Columbus 43210; \\ P. E. Lipps, Department of Plant Pathology, Ohio Agricultural Research and Development Center, The Ohio State \\ University, Wooster 44691; and M. J. Boehm, Department of Plant Pathology, The Ohio State University, Columbus
}

\begin{abstract}
Thomas, S. L., Bonello, P., Lipps, P. E., and Boehm, M. J. 2006. Avenacin production in creeping bentgrass (Agrostis stolonifera) and its influence on the host range of Gaeumannomyces graminis. Plant Dis. 90:33-38.

Avenacinase activity has been shown to be a key factor determining the host range of Gaeumannomyces graminis on oats (Avena sativa). G. graminis var. avenae produces avenacinase, which detoxifies the oat root saponin avenacin, enabling it to infect oats. G. graminis var. tritici does not produce avenacinase and is unable to infect oats. G. graminis var. avenae is also reported to incite take-all patch on creeping bentgrass (Agrostis stolonifera). It is unknown whether creeping bentgrass produces avenacin and if the avenacin-avenacinase interaction influences G. graminis pathogenicity on creeping bentgrass. The root extracts of six creeping bentgrass cultivars were analyzed by fluorimetry, thin-layer chromatography, and high performance liquid chromatography for avenacin content. Avenacin was not detected in any creeping bentgrass cultivars, and pathogenicity assays confirmed that both $G$. graminis var. avenae and G. graminis var. tritici can infect creeping bentgrass and wheat (Triticum aestivum), but only G. graminis var. avenae incited disease on oats. These results are consistent with the root analyses and confirm that avenacinase activity is not required for creeping bentgrass infection by G. graminis.
\end{abstract}

Take-all, caused by Gaeumannomyces graminis (Sacc.) Arx \& D. Olivier, is a devastating root disease of cereal crops and turfgrasses worldwide $(7,23)$. Three varieties of $G$. graminis have been described based on differences in hyphopodium type and ascospore length (21). $G$. graminis var. graminis $(G g g)$ infects rice (Oryza sativa L.) and warm-season grasses, such as St. Augustinegrass (Stenotaphrum secundatum (Walt.) Kuntze) and bermudagrass (Cynodon dactylon (L.) Pers.), and is differentiated from the other varieties of $G$. graminis based on the production of lobed hyphopodia. G. graminis var. avenae (Turner) Dennis ( $G g a)$ and $G$. graminis var. tritici Walker $(G g t)$ infect cool-season graminaceous hosts such as wheat (Triticum aestivum L.) and barley (Hordeum vulgare L.). Gga can also infect oats (Avena sativa L.) and is reported as the causal agent of take-all patch of creeping bentgrass (Agrostis stolonifera L. syn. A. palustris Huds.) $(13,14)$, although $G g t$ has been reported to infect Agrostis spp.

Corresponding author: S. L. Thomas

E-mail: slthomas@CDFA.ca.gov

Current address for S. L. Thomas: California Department of Food and Agriculture, Sacramento, CA 95832 .

Accepted for publication 25 July 2005.

DOI: 10.1094/PD-90-0033

(C) 2006 The American Phytopathological Society
(7). Gga and Ggt are morphologically indistinguishable in culture, as both produce simple hyphopodia, and perithecia are rarely produced (5). If ascospores are produced, generally Gga produces longer ones than does Ggt (21).

Pathogenicity of G. graminis isolates on oats has been shown to be mediated by the avenacin-avenacinase interaction $(1,10,11$, 18,19). Avenacin compounds are fungitoxic saponins produced and stored in the epidermal cells of oat roots (10). The fungitoxic properties of these compounds arise from their ability to form complexes with fungal membrane sterols, leading to leaky cell membranes and fungal cell death (6). Four avenacin compounds have been described (2). The most prevalent and fungitoxic is avenacin A-1, which contains an $\mathrm{N}$-methylanthranilate residue that fluoresces bright blue under UV light $(2,18)$. Gga produces avenacinase, which detoxifies avenacin, enabling this variety to overcome oat root defenses and incite disease $(3,19)$. Although homologous avenacinaselike genes have recently been identified in Ggt and Ggg (12), Ggt isolates do not produce avenacinase and are incapable of infecting Avena spp. that produce avenacin $(10,11)$. Similarly, Gga isolates with disrupted avenacinase genes are unable to infect oats (1). Based on these results, Osbourn and co-workers concluded that avenacinase activity is the key determinant of G. graminis pathogenicity on oats (1).

Clinical diagnosis of take-all patch of creeping bentgrass is typically made based on the observations of foliar symptoms, the presence of dark ectotrophic runner hyphae on the roots, and vascular discoloration (16). Identification of G. graminis isolates from symptomatic creeping bentgrass to the variety level based on morphological characters is rarely performed because it is assumed to be Gga based on previous research. However, in reality, the identity of the causal agent of take-all patch on creeping bentgrass should be examined more closely. It is unknown whether avenacin and avenacinase have a role in the creeping bentgrass-G. graminis interaction; therefore, this study was undertaken to assess the production of avenacin in creeping bentgrass and its role on the host range of $G$. graminis.

\section{MATERIALS AND METHODS}

Avenacin extraction. Creeping bentgrass cultivars Crenshaw, L-93, Penneagle, Penncross, Penn G-2, and Providence were used in this study. Ten milliliters of oat (cv. Armor; $7.3 \mathrm{~g}$ ), wheat (cv. Norm; $5.4 \mathrm{~g}$ ), and bentgrass $(5.8 \mathrm{~g})$ seeds were surfacesterilized in $0.525 \%$ sodium hypochlorite solution containing $0.1 \%$ Tween 20 for 5 min, rinsed three times in sterile distilled water, and placed on $0.3 \%$ water agar in petri dishes for germination (10 petri dishes per species or cultivar). Dishes were incubated in a clear plastic bag at room temperature $\left(25\right.$ to $\left.27^{\circ} \mathrm{C}\right)$ for 3 to 7 days. The terminal 5-mm root tip sections were excised and placed in 1.6- $\mathrm{ml}$ microcentrifuge tubes containing $200 \mu \mathrm{l}$ of $50 \%$ aqueous methanol. Twenty milligrams of root tip tissue were placed in each tube, and due to differences in root mass among the species, batches of 10,20, and 200 root tips from oat, wheat, and bentgrass, respectively, comprised the 20 -mg samples. Root tip samples were stored at $-20^{\circ} \mathrm{C}$ until avenacin extraction.

Avenacin was extracted using a procedure similar to that described by Osbourn et al. (10). Harvested roots were ground with a pestle and hand drill for $30 \mathrm{~s}$, the plant material was pelleted by centrifugation $(45 \mathrm{~s}, 6,400 \mathrm{rpm})$, and $100 \mu \mathrm{l}$ of the supernatant was transferred to a new microcentrifuge tube. Roots were reextracted three times, each with an additional $100 \mu \mathrm{l}$ of $50 \%$ aqueous methanol. A total of $400 \mu \mathrm{l}$ of extract was collected per batch $(20 \mathrm{mg}$ root tips) of roots. Extractions were performed in triplicate, pooled, 
and diluted 20-fold in aqueous methanol (vol/vol). Prior to dilution, crude root extracts were visualized under UV light (302 $\mathrm{nm}$ ), and fluorescence was visually assessed. Emission spectra were measured with an LS-5 Fluorescence Spectrophotometer (Perkin Elmer, Wellesley, MA) using an excitation wavelength of $357 \mathrm{~nm}$ and an emission wavelength of $430 \mathrm{~nm}$. This procedure was repeated three times for each creeping bentgrass cultivar, oats, and wheat.

Prior to spectrophotometric analysis of creeping bentgrass and wheat root extracts, a dilution series of oat root extract was generated (final dilution of 1:2,000) to determine the lower detection limit of the instrument. Fluorescence readings showed that oat dilutions greater than 400-fold were not significantly different from the aqueous methanol solvent. Extracts of wheat and bentgrass were analyzed as 20 fold dilutions and as spiked samples that contained 20-fold diluted wheat or bentgrass extracts and 100-fold diluted oat extract. The spiked samples were produced to ensure all samples would have fluorescence readings significantly greater than the solvent control, which would allow for detection of otherwise undetectable levels of avenacin, and ensure there was no quenching of the fluorescence in any of the samples.

Statistical analyses were performed using Minitab Statistical Software (Minitab Inc., State College, PA). The nonparametric Kruskal Wallis test (15) was used to determine the effect of plant species or cultivar on root extract fluorescence, and mean separations were based on the differences in mean ranks for root extracts using the least significant difference (LSD) at $P=0.05$. Median fluorescence measurements corresponding to mean ranks for each plant species or cultivar were reported.

Thin-layer chromatography (TLC) analysis and avenacin bioassay. The TLC and avenacin bioassays were performed as described by Osbourn et al. (9). All creeping bentgrass cultivars, wheat, and oats were used in this assay. Root tips were extracted with $50 \%$ aqueous methanol as previously described. One hundred microliters of the crude root extracts were loaded (10- $\mu$ l aliquots) onto two $250-\mu \mathrm{m}$ thickness polyester silica gel TLC plates ( 2 to $25 \mu \mathrm{m}$ mean particle size; Sigma Chemical Corp., St. Louis, MO). Plates were developed with chloroform:methanol:water (13:6:1; vol/vol/vol). Fluorescent compounds were visualized under UV light $(302 \mathrm{~nm})$, and the location of each fluorescent spot was marked on the reverse side of the plate. $R_{f}$ values were calculated for each spot.

Gga isolate MB 013 and Ggt isolate MB 029 (Table 1) were used to assess the presence of inhibitory compounds in root extracts. Five milliliters of sterile potato dextrose broth (PDB; Becton Dickinson, Cockeysville, MD) was sprayed onto the developed TLC plates to provide a suitable substrate for $G$. graminis growth. Each TLC plate was inoculated with 15 agar plugs ( $8 \mathrm{~mm}$ diameter) taken from the margin of actively growing cultures, placed equidistant from each other, and incubated in sterile plastic bags for 2 weeks at room temperature in the dark. Observations of fungal colonization of the plates were made at 7 and 14 days. Areas

Table 1. List of Gaeumannomyces graminis isolates used in this study

\begin{tabular}{|c|c|c|c|c|}
\hline \multirow[b]{2}{*}{ Isolate } & \multirow[b]{2}{*}{ Host } & \multicolumn{3}{|c|}{ Origination information } \\
\hline & & Location & Source & $\begin{array}{c}\text { Designations } \\
\text { of other researchers }\end{array}$ \\
\hline \multicolumn{5}{|c|}{ G. graminis var. avenae } \\
\hline MB 001 & Agrostis stolonifera & Ohio & This study & \\
\hline MB 002 & A. stolonifera & Ohio & This study & \\
\hline MB 013 & A. stolonifera & New Jersey & B. Clarkew & Mat 1 \\
\hline MB 014 & A. stolonifera & Pennsylvania & This study & \\
\hline MB 019 & A. stolonifera & Ohio & N. Tisserat ${ }^{\mathrm{x}}$ & 314 \\
\hline MB 0214 & A. stolonifera & Ohio & This study & \\
\hline MB 032 & A. stolonifera & Ohio & This study & \\
\hline MB 0317 & Agrostis spp. & Indiana & R. Smileyy & KS 150 \\
\hline \multicolumn{5}{|c|}{ G. graminis var. tritici } \\
\hline MB 0126 & Triticum aestivum & Ohio & This study & \\
\hline MB 025 & T. aestivum & Virginia & E. Stromberg ${ }^{\mathrm{z}}$ & CS1 \\
\hline MB 026 & T. aestivum & Montana & E. Stromberg & M1 \\
\hline MB 029 & T. aestivum & Virginia & E. Stromberg & CB1 \\
\hline MB 0311 & T. aestivum & Washington & R. Smiley & 99114 \\
\hline MB 0312 & T. aestivum & Washington & R. Smiley & 99710 \\
\hline MB 0313 & T. aestivum & Washington & R. Smiley & 99401 \\
\hline MB 0314 & T. aestivum & Washington & R. Smiley & 99111 \\
\hline
\end{tabular}

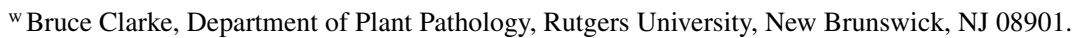

${ }^{x}$ Ned Tisserat, Department of Plant Pathology, Kansas State University, Manhattan, KS 66506.

y Richard Smiley, Columbia Basin Agricultural Research Center, Oregon State University, Pendleton, OR 97801.

${ }^{\mathrm{z}}$ Erik Stromberg, Department of Plant Pathology, Physiology, and Weed Science, Virginia Polytechnic Institute and State University, Blacksburg, VA 24061. void of fungal growth at 14 days were scraped off the plate and eluted with $200 \mu \mathrm{l}$ of $50 \%$ aqueous methanol. Eluates were visualized under UV light $(302 \mathrm{~nm})$ to check for fluorescence and stored at $-20^{\circ} \mathrm{C}$ until HPLC analysis.

High performance liquid chromatography (HPLC) analysis of root extracts. Root extracts from oats, wheat, and the creeping bentgrass cultivar Penneagle were analyzed by HPLC using a procedure similar to that described by Papadopoulou et al. (11). The eluted inhibitory compounds from the TLC plate and TLC-purified avenacin A-1 (donated by Anne Osbourn, The Sainsbury Laboratory, John Innes Centre, Norwich, UK) were also analyzed. Samples were analyzed using a Waters (Milford, MA) 2690 separations module and a 474 scanning fluorescence detector. The system was managed by a workstation running version 3.20 of Waters Millennium HPLC software. Injections, consisting of $20 \mu \mathrm{l}$ of the 20 -fold diluted root extracts or 100-fold diluted avenacin A-1 and the eluate from the TLC plate, were separated on a Waters Xterra RP18, $5 \mu \mathrm{m}, 4.6 \times 150$ $\mathrm{mm}$ column under isocratic conditions in $75 \%$ methanol at a flow rate of $1 \mathrm{ml} \mathrm{min}^{-1}$. The fluorescence detector was set at an excitation wavelength of $357 \mathrm{~nm}$ and an emission wavelength of $430 \mathrm{~nm}$. The autosampler temperature was $4^{\circ} \mathrm{C}$ and column temperature was $30^{\circ} \mathrm{C}$ for all analyses. Total run time was 14 min per sample.

Maintenance and cultivation of fungal isolates. Sixteen $G$. graminis isolates (8 $G g a$ and $8 G g t$ ) were used in this study (Table 1). All isolates were maintained on $1 / 5$ strength potato dextrose agar (1/5 PDA; Becton Dickinson) amended with both penicillin and streptomycin sulfate (Sigma Chemical Corp.) at $100 \mu \mathrm{g} \mathrm{ml}^{-1}$. Isolates were grown in the dark at room temperature $\left(25\right.$ to $\left.27^{\circ} \mathrm{C}\right)$ and stored as colonized agar disks (5 $\mathrm{mm}$ diameter) at $-80^{\circ} \mathrm{C}$ in $1 / 5$ strength PDB amended with $15 \%$ glycerol and as colonized agar plates at $4^{\circ} \mathrm{C}$ covered with sterilized mineral oil (22). Isolates were transferred monthly to freshly prepared media and maintained in culture for a maximum of 6 months (six generations) then reisolated from stored cultures.

Isolates were identified to the variety level using morphological characters (i.e., mean ascospore lengths and hyphopodium type) and pathogenicity on wheat and oats as described by Turner (17) and Walker (20) for variety avenae and tritici, respectively. Isolates used in this study exhibited traits typical of Gga or Ggt.

Pathogenicity assays. For each Gga or Ggt isolate, colonized white proso millet (Panicum milaceum L.) seed was used as inoculum for all assays. Eighty milliliters $(56 \mathrm{~g})$ of millet seeds were added to a 250 $\mathrm{ml}$ Erlenmeyer flask with $60 \mathrm{ml}$ of distilled water. The seeds were soaked overnight and the excess water was decanted. Flasks 
were plugged with cotton, autoclaved for $50 \mathrm{~min}$, and cooled in a laminar flow hood for 4 to $6 \mathrm{~h}$ prior to inoculation with 12 agar plugs ( $8 \mathrm{~mm}$ diameter) taken from the margin of an actively growing culture of G. graminis. Flasks were incubated at room temperature $\left(23\right.$ to $\left.25^{\circ} \mathrm{C}\right)$ for 14 to 21 days and were shaken every 4 to 5 days to ensure all of the seeds were colonized. Inoculum was dried in paper bags at room temperature for 3 to 4 days and shaken daily to break up clumps. Forty to fifty colonized seeds were plated on 1/5 PDA and 1/5 PDA amended with rifampicin (100 $\mathrm{g} \mathrm{ml}^{-1}$; Sigma Chemical Corp.) prior to use to ensure that the inoculum was not contaminated and $95 \%$ or more of the millet seeds were colonized (i.e., $\geq 38 / 40$ plated millet seeds produced $G$. graminis growth). Only those inocula free of contamination and with a sufficient proportion of colonized seeds were used. Inocula were stored at room temperature and used for up to 6 weeks after production.

Assays were established using Conetainers $(3.8 \mathrm{~cm}$ diameter $\times 21 \mathrm{~cm}$ depth; SC-10 Super Cell, Ray Leach Conetainers, Stuewe and Sons, Corvallis, OR) plugged with cotton and held upright in a tray (RL98Tray, Ray Leach Cone-tainers, Stuewe and Sons, Corvallis, OR). One Cone-tainer was set up per plant species and fungal isolate for each experimental repetition. Infested rooting media was produced for each Cone-tainer by thoroughly mixing 0.0 or $1.0 \mathrm{~g}$ of colonized millet seed into $150 \mathrm{ml}$ of sterilized mason sand (autoclaved for $90 \mathrm{~min}$ ). The inoculated sand was covered with $5 \mathrm{ml}$ of sterilized sand. Noninfested rooting medium consisted of sterilized sand only. Each Cone-tainer was then seeded with $60.5 \mathrm{mg}$ of creeping bentgrass cv. Penneagle or four oat (cv. Armor) or wheat (cv. Norm) seeds. Seeds were covered with $5 \mathrm{ml}$ of sterilized sand, then fertilized with $30.2 \mathrm{mg}$ of starter fertilizer (20-27-5; N-P-K; Scotts Co., Marysville, $\mathrm{OH})$. Cone-tainers were randomized within the tray, watered, and covered with plastic wrap until germination occurred. Cone-tainers with oats and wheat were thinned to two seedlings per Conetainer after germination. Cone-tainers were incubated in a controlled environmental chamber set to provide a $12-\mathrm{h}$ photoperiod $\left(12 \mathrm{~h} 18^{\circ} \mathrm{C} ; 12 \mathrm{~h} 12^{\circ} \mathrm{C}\right)$ for 28 days. Conetainers were watered every other day.

Disease was assessed at 28 days. Disease severity was assessed on oat and wheat plants using the rating scale of Weller and Cook (22) in which: $0=$ no disease; $1=$ one or two lesions on the roots of a given plant; $2=50$ to $100 \%$ of the roots with one or more lesions each; $3=$ all roots with lesions and some evidence of infection on the stem; 4 = lesions abundant and beginning to coalesce on the stem; and $5=$ plants dead or nearly so. Measurements made on creeping bentgrass included turfgrass height $(\mathrm{cm})$, percent symptomatic area of the foliage, root length $(\mathrm{cm})$, and root disease incidence. The percent symptomatic area was visually assessed as the relative percentage of creeping bentgrass leaves exhibiting chlorosis or tip dieback per Cone-tainer. Disease incidence was calculated by dividing the total number of visibly diseased roots (roots with discolored vascular systems) by the total number of roots observed from 50 bentgrass plants (200 to 300 roots per Cone-tainer were typically observed). This alternate disease rating system for creeping bentgrass was developed and used due to the small size of the root system of creeping bentgrass and the fact that root lesions on this host are not easily discerned as compared with wheat or oats. This experiment was repeated five times, and each repetition was considered a replication. Each replication was treated as a block, and the experiment was analyzed as a randomized complete block.

Fungal variety effect (i.e., Gga versus $G g t$ versus control) on creeping bentgrass plant height, root length, symptomatic area, and fungal isolate effect on creeping bentgrass root disease incidence was determined with analysis of variance (ANOVA) using Minitab. Symptomatic leaf area and root disease incidence data were arcsine-transformed prior to ANOVA. Mean separations were performed based on $\operatorname{LSD}(P=0.05)$ of means for plant height and root length and transformed means for symptomatic area and disease incidence.

The non-parametric Kruskal Wallis test (15) was used to determine the fungal isolate effect on disease severity of wheat and oat. Mean separations were based on the differences in mean ranks for each isolate using LSD $(P=0.05)$. Median disease ratings corresponding to mean ranks for each isolate were presented. The Spearman rank correlation (15) between mean disease incidence on bentgrass and median disease severity rating in wheat across all isolates was calculated to determine the consistency of isolate pathogenicity across susceptible host species.

\section{RESULTS}

Avenacin production. Crude oat root extracts fluoresced bright blue under UV light, indicating avenacin compounds were extracted. None of the crude root extracts from any of the creeping bentgrass cultivars or wheat fluoresced under UV (data not shown).

Fluorescence measured with the spectrophotometer in the 20 -fold diluted oat extract sample was significantly greater $(\mathrm{H}$ $=47.68, \mathrm{df}=16, P<0.001)$ than the aqueous methanol control and all other plant samples (Table 2). The fluorescence measured from the 20-fold diluted root extracts of the creeping bentgrass cultivars and wheat did not significantly differ from the aqueous methanol control. No differences were detected between the spiked bentgrass and spiked wheat samples and the 100-fold diluted oat sample (Table 2), indicating there was no quenching of fluorescence by creeping bentgrass or wheat extracts nor was avenacin present in low (below detectable) levels.

No fluorescence was observed for either wheat or creeping bentgrass when root extracts were separated on TLC and visualized under long wave UV. A bright blue spot was observed in the crude oat root extract lane (Fig. 1A). The $R_{f}$ value of the spot under the TLC conditions was 0.80 . Fungal growth was inhibited in the oat extract lane when the developed TLC plate was inoculated with $G g t$ isolate MB 029 (Fig. 1B), whereas the TLC plate inoculated with $G g a$ isolate MB 013 was completely colonized (Fig. 1C).

HPLC analyses showed two peaks (2.3 and $2.8 \mathrm{~min}$ ) to be common from all three plant species (Fig. 2A). No additional peaks were observed in the wheat or creeping bentgrass root extracts. Oat extracts generated two additional peaks with retention times of 3.4 and $4.5 \mathrm{~min}$, respectively. The fluorescent eluate recovered from the TLC plate and the purified avenacin compound produced extremely similar HPLC profiles (Fig. 2B), each containing two major peaks with retention times comparable to those in the crude oat root extract (Fig. 2A). The fluorescent eluate recovered

Table 2. Fluorimetric analysis of root extracts from wheat, creeping bentgrass, and oats

\begin{tabular}{lc}
\hline Extractsw $^{\mathbf{w}}$ & Fluorescence $^{\mathbf{x}}$ \\
\hline Methanol & $2.0 \mathrm{a}^{\mathrm{y}}$ \\
Wheat & $3.4 \mathrm{a}$ \\
Oat & $97.9 \mathrm{c}$ \\
Creeping bentgrass cultivars & \\
Crenshaw & $2.5 \mathrm{a}$ \\
L-93 & $2.7 \mathrm{a}$ \\
Penn G-2 & $2.6 \mathrm{a}$ \\
Penncross & $2.4 \mathrm{a}$ \\
Penneagle & $2.4 \mathrm{a}$ \\
Providence & $2.6 \mathrm{a}$ \\
Spiked extracts & \\
Spiked wheat & $21.7 \mathrm{~b}$ \\
Oat (1/100 dilution) & $24.2 \mathrm{~b}$ \\
Spiked Crenshaw & $23.8 \mathrm{~b}$ \\
Spiked L-93 & $24.2 \mathrm{~b}$ \\
Spiked Penn G-2 & $23.6 \mathrm{~b}$ \\
Spiked Penncross & $23.2 \mathrm{~b}$ \\
Spiked Penneagle & $23.2 \mathrm{~b}$ \\
Spiked Providence & $24.1 \mathrm{~b}$ \\
\hline
\end{tabular}

"Wheat, oat, and bentgrass root extracts were diluted 20 -fold (vol/vol) in $50 \%$ aqueous methanol.

${ }^{\mathrm{x}}$ Excitation wavelength $=357 \mathrm{~nm}$ and emission wavelength $=430 \mathrm{~nm}$.

y Multiple comparisons of mean ranks are based on the Kruskal Wallis test. Corresponding median fluorescent measurements of root extracts are shown. Values followed by the same letter are not significantly different at $P=0.05$.

${ }^{\mathrm{z}}$ Spiked extracts contained 20 -fold diluted wheat or bentgrass extract and 100-fold diluted oat extract. 
in this study also exhibited a peak at 3.0 min that was not present in any of the other samples. This peak may have been the result of differences in the TLC plates used to purify the avenacin compounds.

Pathogenicity of G. graminis isolates. All Gga isolates infected creeping bentgrass, wheat, and oats (Table 3), but only creeping bentgrass was significantly $(P<$ 0.05 ) diseased by all $\mathrm{Gga}$ isolates as compared with the controls. Three $G g t$ isolates generated significantly $(P<0.05)$ greater levels of disease on wheat and creeping bentgrass as compared with the noninoculated control, and none of the Ggt isolates infected oats. Among isolates of the same variety, significant differences were observed in the levels of disease incidence on creeping bentgrass $(P<0.001)$ and disease severity on wheat $(\mathrm{H}=64.58, \mathrm{df}=21, P<$ $0.001)$ and oat $(\mathrm{H}=56.79$, df $=21, P<$ 0.001 ) for $G g a$. Several of the Ggt isolates (e.g., MB 026, MB 029, and MB 0314) caused similar levels of disease incidence on creeping bentgrass as compared with Gga. Most of the Gga isolates caused as severe or greater disease on wheat as compared with $G g t$ isolates. The ability of $G$. graminis isolates to cause disease incidence on creeping bentgrass was strongly correlated with the isolates' ability to cause disease on wheat based on a Spearman rank correlation of 0.93 .

Irrespective of variety, inoculation with $G$. graminis resulted in creeping bentgrass plants that were significantly $(P<0.05)$ shorter than the control plants (Table 4). Most of the Gga isolates caused creeping bentgrass plants to have significantly $(P<$ $0.05)$ shorter roots and greater symptomatic leaf areas as compared with the con-
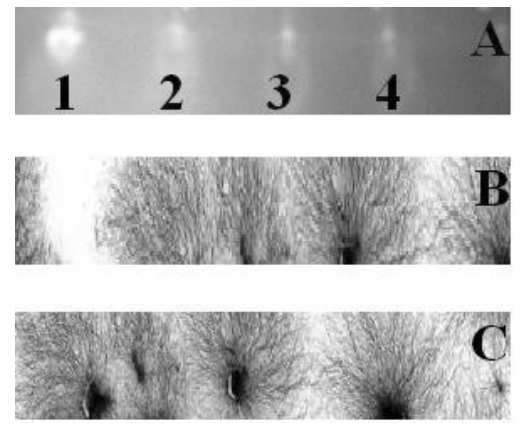

Fig. 1. Thin-layer chromatography (TLC) analysis and fungal bioassay of root extracts. A, Developed TLC plate under UV illumination. Crude root extracts $(100 \mu \mathrm{l})$ were separated on TLC plates using chloroform:methanol:water (13:6:1, vol/vol/vol) solvent. Lanes: 1 : oat root extracts; 2: wheat root extract; 3: 'Penneagle' creeping bentgrass root extracts; $4: 50 \%$ aqueous methanol. Fluorescent compounds correspond to the oat lane. No other fluorescent compounds were observed. B, Growth of Gaeumannomyces graminis var. tritici isolate MB 029 on the developed plate. No growth occurred in the area where fluorescence was observed. C, Growth of G. graminis var. avenae isolate MB 013 on the developed plate. No inhibition was observed. trol and Ggt-inoculated plants. Creeping bentgrass receiving Ggt inoculum had root lengths and symptomatic leaf areas comparable to control plants (Table 4). ANOVA results showed that replication did not have a significant effect on any disease measurements taken from creeping bentgrass, wheat, or oats (data not shown).

\section{DISCUSSION}

Avenacin was not detected in any of the creeping bentgrass cultivars evaluated in this study when root extracts were analyzed by fluorimetry, TLC, and HPLC. Neither Ggt nor Gga growth was inhibited by the TLC-separated root extracts of creeping bentgrass or wheat. However, consistent with previous studies $(2,10,19)$, a fluorescent compound present in oat roots was inhibitory to Ggt growth but not to $G g a$ growth. Similar results were shown in the pathogenicity assays, as none of the Ggt isolates infected oats but all of the Gga isolates did. HPLC analyses showed that the inhibitory fluorescent eluate recovered from the TLC plate was avenacin, as the eluate recovered in this study and the purified avenacin A-1 generated extremely similar profiles. Slight differences in the HPLC profiles were probably the result of differences in the properties of TLC plates used to separate root extracts (9). In addition, there was a slight shift in the retention times observed for compounds in the oat root extract as compared with the purified avenacin compounds. This may have been the result of HPLC analyses being performed on different days or the effect of TLC purification. The results presented in this study were similar to those previously reported for oat and wheat extracts $(2,10,18)$ and support previous conclusions that avenacin production is most likely limited to Avena spp. $(2,10)$.

Little is known regarding creeping bentgrass defense mechanisms. In other graminaceous plants, secondary metabolites, such as cyclic hydroxamic acids and saponins, have been shown to have key roles in the plant defenses (6). Wheat, maize, and rye have been shown to produce cyclic hydroxamic acids, in particular 2,4-dihydroxy-1,4-benzoxazin-3-one and 2,4-dihydroxy-7-methoxy-1,4-benzoxazin-
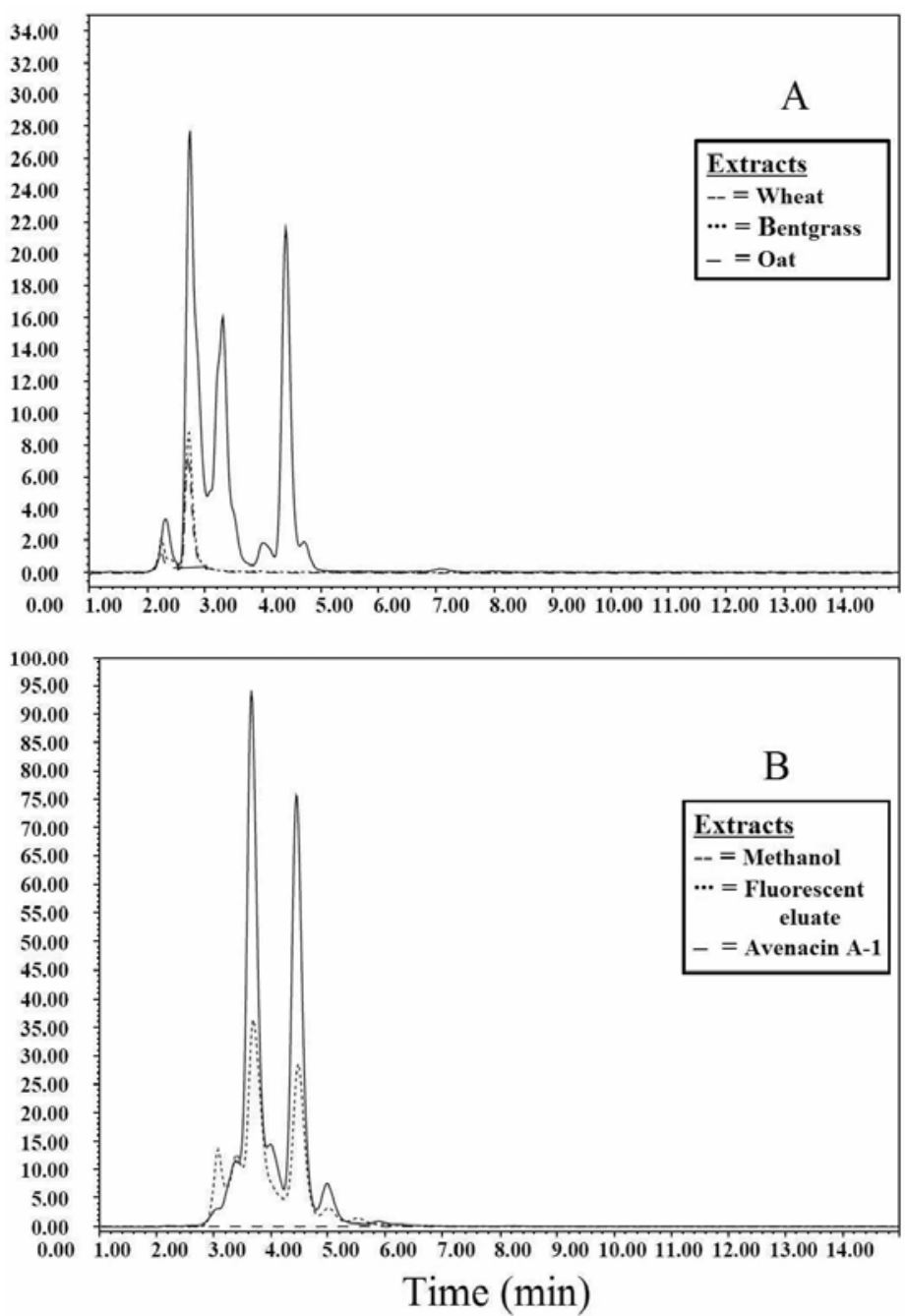

Fig. 2. High performance liquid chromatography analyses of root extracts. A, purified avenacin A-1 (kindly donated by Anne Osbourn) and B, the fluorescent eluate from the thin-layer chromatography plate. The y-axis represents fluorescence. 
3-one (DIBOA and DIMBOA, respectively), which when activated by plant defenses are inhibitory to a number of fungal and bacterial pathogens (4). Similarly, the antifungal effects of avenacin, an oat root saponin, have been well documented (1-3,9-11,18,19). Although the chemistries differ, the cyclic hydroxamic acids and saponins are used in similar fashions (i.e., preformed conjugates are produced and stored in cells until infection, at which time the conjugates are activated and released). Mutations of these systems have shown that reduced expression of these metabolic genes results in an increase of susceptibility and host infections $(4,11)$. For the pathogen, overcoming host defenses is one key to successful infection. The avenacin-avenacinase interaction has been shown to mediate the oat-G. graminis interaction with the result that only $G$. graminis isolates with functional avenacinase genes are capable of infecting oats.

Given that avenacin is not produced in creeping bentgrass roots, avenacinase activity does not appear to be required for pathogenicity of $G$. graminis isolates on creeping bentgrass. This study confirmed previous reports (8) that Ggt is able to infect creeping bentgrass. Irrespective of variety, inoculation with $G$. graminis significantly $(P<0.05)$ reduced creeping bentgrass height; however, only inoculations with $G g a$ significantly $(P<0.05)$ reduced root length and increased symptomatic foliar areas. These results indicate that if Ggt incites take-all patch on creeping bentgrass under field conditions, the area affected may not be great enough to warrant sample taking, isolate recovery, and identification as compared with infections incited by $G g a$. Field studies are in progress to assess the ability of Ggt isolates to infect creeping bentgrass under natural conditions.

In this study, there was a strong correlation detected between an isolate's ability to infect creeping bentgrass and wheat $\left(\mathrm{r}_{\mathrm{s}}=\right.$ $0.93)$. This correlation indicates that the Gga isolates are more aggressive on graminaceous hosts as compared with the $G g t$ isolates, as they generated greater levels of disease severity or incidence and greater symptomatic plant areas. However, only 16 isolates ( $8 \mathrm{Gga}$ and $8 \mathrm{Ggt}$, respectively) were used in this study, and this is a small population to use to make generalities regarding the pathogenic abilities of $G$. graminis varieties. Significant $(P<0.001)$ differences were detected in the levels of disease incidence on creeping bentgrass and disease severity on wheat and oats (for $G g a$ ) among isolates of the same variety, illustrating that there is a range in the pathogenic abilities of each variety on a given host. Further studies involving larger isolate collections of $G$. graminis are needed before generalities of varietal aggressiveness toward graminaceous hosts can be made.
In additional studies (S. L. Thomas and M. J. Boehm, unpublished data), all of the G. graminis isolates recovered from symptomatic creeping bentgrass were identified as var. avenae using morphological and molecular characteristics, illustrating the prevalence of this variety as the causal agent of take-all patch on creeping bentgrass. Perhaps this is the result of differences in the abilities of each variety to colonize weedy grass species which may serve as asymptomatic reservoirs of the pathogen. Gga has been shown to have a greater weedy grass host range than $G g t$ (14) which may maintain Gga populations as lands are renovated and developed into golf courses. Alternatively, avenacinase may serve an as yet unknown function in the infection process of creeping bentgrass.

Table 3. Take-all incidence and severity on graminaceous hosts

\begin{tabular}{|c|c|c|c|}
\hline \multirow[b]{2}{*}{ Isolate } & \multicolumn{3}{|c|}{ Host } \\
\hline & $\begin{array}{c}\text { Bentgrass } \\
\left.\text { (disease incidence }^{w}\right)\end{array}$ & $\begin{array}{c}\text { Wheat } \\
\left(\text { disease severity }^{x}\right)\end{array}$ & $\begin{array}{c}\text { Oat } \\
\left(\text { disease severity }^{x}\right)\end{array}$ \\
\hline Control & $0 \mathrm{a}^{\mathrm{y}}$ & $0.0 \mathrm{a}^{\mathrm{z}}$ & $0.0 \mathrm{a}^{\mathrm{z}}$ \\
\hline \multicolumn{4}{|c|}{ G. graminis var. avenae } \\
\hline MB 001 & 20 def & $3.5 \mathrm{abcd}$ & $2.0 \mathrm{ab}$ \\
\hline MB 002 & $27 \mathrm{fgh}$ & $5.0 \mathrm{~cd}$ & $2.5 \mathrm{ab}$ \\
\hline MB 013 & $33 \mathrm{~h}$ & $5.0 \mathrm{~cd}$ & $3.0 \mathrm{~b}$ \\
\hline MB 014 & 18 cde & $3.5 \mathrm{bcd}$ & $2.5 \mathrm{ab}$ \\
\hline MB 019 & 18 cde & $2.5 \mathrm{abc}$ & $1.5 \mathrm{ab}$ \\
\hline MB 0214 & $45 \mathrm{i}$ & $5.0 \mathrm{~d}$ & $5.0 \mathrm{~b}$ \\
\hline MB 032 & $48 \mathrm{i}$ & $5.0 \mathrm{~d}$ & $5.0 \mathrm{~b}$ \\
\hline MB 0317 & $29 \mathrm{gh}$ & $5.0 \mathrm{~d}$ & $4.0 \mathrm{~b}$ \\
\hline \multicolumn{4}{|c|}{ G. graminis var. tritici } \\
\hline MB 0126 & $7 \mathrm{ab}$ & $3.0 \mathrm{abcd}$ & $0.0 \mathrm{a}$ \\
\hline MB 025 & $1 \mathrm{a}$ & $2.5 \mathrm{abc}$ & $0.0 \mathrm{a}$ \\
\hline MB 026 & 24 efg & $4.5 \mathrm{bcd}$ & $0.0 \mathrm{a}$ \\
\hline MB 029 & $14 \mathrm{bcd}$ & $4.0 \mathrm{bcd}$ & $0.0 \mathrm{a}$ \\
\hline MB 0311 & $2 \mathrm{a}$ & $1.5 \mathrm{ab}$ & $0.0 \mathrm{a}$ \\
\hline MB 0312 & $1 \mathrm{a}$ & $1.5 \mathrm{ab}$ & $0.0 \mathrm{a}$ \\
\hline MB 0313 & $1 \mathrm{a}$ & $1.0 \mathrm{ab}$ & $0.0 \mathrm{a}$ \\
\hline MB 0314 & $12 \mathrm{bc}$ & $3.5 \mathrm{bcd}$ & $0.0 \mathrm{a}$ \\
\hline
\end{tabular}

${ }^{w}$ Mean disease incidence of creeping bentgrass roots was calculated by dividing the total number of visibly diseased roots (roots with discolored vascular systems) by the total number of roots observed from 50 plants.

${ }^{x}$ Median disease severity rating on wheat and oats. Severity was assessed on a rating scale of 0 to 5 , in which $0=$ no disease and $5=$ a dead plant.

y Multiple comparisons of means are based on arcsine-transformed values. However, mean percentages are shown. Values followed by the same letter are not significantly different based on the LSD $(P=$ $0.05)$.

$\mathrm{z}$ Two oat and wheat plants were rated per Cone-tainer and the average disease severity rating was used in analysis. Multiple comparisons of mean ranks are based on the Kruskal Wallis test. Corresponding median severity ratings are shown. Values followed by the same letter within a column are not significantly different at $P=0.05$.

Table 4. Effect of Gaeumannomyces graminis variety on creeping bentgrass height, root length, and observed symptomatic area

\begin{tabular}{|c|c|c|c|c|c|c|}
\hline \multirow[b]{3}{*}{ Variety } & \multicolumn{6}{|c|}{ Disease assessment } \\
\hline & \multicolumn{2}{|c|}{ Bentgrass height $(\mathrm{cm})$} & \multicolumn{2}{|c|}{ Root length (cm) } & \multicolumn{2}{|c|}{ Symptomatic area } \\
\hline & Mean & $\mathbf{S E}^{\mathrm{x}}$ & Mean & SE & Mean & SE \\
\hline Control & $8.0 \mathrm{a}^{\mathrm{y}}$ & 0.23 & $7.3 \mathrm{a}$ & 0.33 & $0.0 \mathrm{a}^{\mathrm{z}}$ & 0.00 \\
\hline G. graminis var. avenae & $4.8 \mathrm{c}$ & 0.24 & $5.1 \mathrm{~b}$ & 0.28 & $31.9 \mathrm{~b}$ & 4.30 \\
\hline G. graminis var. tritici & $5.9 \mathrm{~b}$ & 0.19 & $6.8 \mathrm{a}$ & 0.20 & $3.2 \mathrm{a}$ & 0.99 \\
\hline
\end{tabular}

x Standard error of the mean, calculated as the standard deviation/ $(\sqrt{ } N) . N=5$ for the controls and 40 for the variety treatments.

y Values followed by the same letter are not significantly different based on the LSD $(P=0.05)$.

${ }^{\mathrm{z}}$ Multiple comparisons of means for symptomatic areas are based on arcsine-transformed values. However, mean percentages are shown. Values followed by the same letter are not significantly different based on the $\operatorname{LSD}(P=0.05)$. 
studies regarding creeping bentgrasspathogen interactions may lead to the elucidation of host chemical defenses present and perhaps lead to the engineering of natural disease suppression in stands of creeping bentgrass.

\section{ACKNOWLEDGMENTS}

We gratefully acknowledge grant support from the Ohio Turfgrass Foundation. We thank Anne Osbourn for her donation of purified avenacin A1. We also gratefully acknowledge L. H. Rhodes, B. B. McSpadden Gardener, and G. L. Wang for their critical review of this manuscript and $\mathrm{L}$. V. Madden for statistical advice. Support for this study was provided by state and federal funds appropriated to the Ohio Agricultural Research and Development Center, the Ohio State University.

\section{LITERATURE CITED}

1. Bowyer, P., Clarke, B. R., Lunness, P., Daniels, M. J., and Osbourn, A. E. 1995. Host range of a plant pathogenic fungus determined by a saponin detoxifying enzyme. Science 267:371374.

2. Crombie, W. M. L., and Crombie, L. 1986. Distribution of avenacins A-1, A-2, B-1, and B-2 in oat roots: Their fungicidal activity towards 'take-all' fungus. Phytochemistry 25:2069-2073.

3. Crombie, W. M. L., Crombie, L., Green, J. B., and Lucas, J. A. 1986. Pathogenicity of 'Takeall' fungus to oats: Its relationship to the concentration and detoxification of the four avenacins. Phytochemistry 25:2075-2083.

4. Frey, M., Chomet, P., Glawischnig, E., Stettner, C., Grun, S., Winklmair, A., Eisenreich, W., Bacher, A., Meeley, R. B., Briggs, S. P., Simcox, K., and Gierl, A. 1997. Analysis of chemical plant defense mechanism in grasses. Science 277:696-699.

5. Holden, M., and Hornby, D. 1981. Methods of producing perithecia of Gauemannomyces graminis and their applications to related fungi. Trans. Br. Mycol. Soc. 77:107-118.

6. Morissey, J. P., and Osbourn, A. E. 1999. Fungal resistance to plant antibiotics as a mechanism of pathogenesis. Microbiol. Mol. Biol. Rev. 63:708-724.

7. Nilsson, H. E., and Smith, J. D. 1981. Take-all of grasses. Pages 433-438 in: Biology and control of take-all. M. J. C. Asher and P. J. Shipton, eds. Academic Press, New York.

8. Osbourn, A., Bowyer, P., Lunness, P., Clarke, B., and Daniels, M. 1995. Fungal pathogens of oat roots and tomato leaves employ closely related enzymes to detoxify different host plant saponins. Mol. Plant-Microbe Interact. 8:971978.

9. Osbourn, A. E., Clarke, B. R., Dow, J. M., and Daniels, M. J. 1991. Partial characterization of avenacinase from Gaeumannomyces graminis var. avenae. Physiol. Mol. Plant Pathol. 38:301-312.

10. Osbourn, A. E., Clarke, B. R., Lunness, P., Scott, P. R., and Daniels, M. J. 1994. An oat species lacking avenacin is susceptible to infection by Gaeumannomyces graminis var. tritici. Physiol. Mol. Plant Pathol. 45:457-467.

11. Papadopoulou, K., Melton, R. E., Leggett, M., and Daniels, M. J. 1999. Compromised disease resistance in saponin deficient plants. Proc. Natl. Acad. Sci. 96:12923-12928.

12. Rachdawong, S., Cramer, C. L., Grabau, E. A., Stromberg, V. K., Lacy, G. H., and Stromberg, E. L. 2002. Gaeumannomyces graminis vars. avenae, graminis, and tritici identified using PCR amplification of avenacinase-like genes. Plant Dis. 86:652-660.

13. Smiley, R. W., Dernoeden, P. H., and Clarke,
B. B. 1992. Compendium of Turfgrass Diseases, 2nd ed. American Phytopathological Society, St. Paul, MN.

14. Smith, J. D., Jackson, N., and Woolhouse, A R. 1989. Fungal Diseases of Amenity Turf Grasses, 3rd ed. E. \& F. N. Spon Ltd., New York.

15. Sprent, P., and Smeeton, N. C. 2001. Applied Nonparametric Statistical Methods, 3rd ed. Chapman \& Hall, Boca Raton, FL.

16. Stowell, L. J., and Gerlenter, W. D. 2001. Diagnosis of turfgrass diseases. Annu. Rev. Phytopathol. 39:135-155.

17. Turner, E. M. 1940. Ophiobolus graminis Sacc. var. avenae var. n., as the cause of takeall or whiteheads of oats in Wales. Trans. Br Mycol. Soc. 24:269-281.

18. Turner, E. M. 1960. The nature of the resistance of oats to the take-all fungus. III. Distribution of the inhibitor in oat seedlings. J. Exp. Bot. 33:403-412

19. Turner, E. M. 1961. An enzymic basis for pathogenic specificity in Ophiobolus graminis. J. Exp. Bot. 12:169-175.

20. Walker, J. 1972. Type studies on Gaeumannomyces graminis and related fungi. Trans. Br. Mycol. Soc. 58:427-457.

21. Walker, J. 1981. Taxonomy of take-all fungi and related genera and species. Pages 15-74 in: Biology and Control of Take-all. M. J. C. Asher and P. J. Shipton, eds. Academic Press, New York.

22. Weller, D. M., and Cook, R. J. 1983. Suppression of take-all of wheat by seed treatment with fluorescent pseudomonads. Phytopathology 73:463-469.

23. Yarham, D. J. 1981. Practical aspects of epidemiology and control. Pages 353-384 in: Biology and Control of Take-all. M. J. C. Asher and P. J. Shipton, eds. Academic Press, New York. 